\title{
Atopic dermatitis and risk of autoimmune diseases: a systematic review and meta-analysis
}

\author{
Zhiyu Lu, Ni Zeng, Yuxin Cheng, Yihe Chen, Yueyue Li, Qian Lu, Qingyue Xia and Dan Luo*
}

\begin{abstract}
Background: Atopic dermatitis is the most common chronic inflammatory skin disease and presents a major public health burden worldwide. Recent observational studies revealed the potential association between atopic dermatitis with autoimmune disorders. However, there is no meta-analysis of the prevalence or incidence of autoimmune diseases in atopic dermatitis. Therefore, considering the potential clinical implications of these associations, we aimed to assess the risk of autoimmune diseases in patients with atopic dermatitis using this method.

Methods: PubMed, Embase, and Web of Science were searched from inception to October, 2020. Observational studies which provided estimate effects with $95 \% \mathrm{Cl}$ or raw data were included. The quality of selected studies was evaluated using the Newcastle-Ottawa Scale. Odds ratio and relative risks were pooled using a random effects model and expressed with 95\% confidence intervals.

Results: Fourteen observational studies were included in this systematic review and meta-analysis. The randomeffects meta-analysis of case-control and cross-sectional studies showed a significant association of atopic dermatitis with mutiple autoimmune diseases, including alopecia areata, celiac disease, Crohn's disease, rheumatoid arthritis, systematic lupus erythematosus, ulcerative colitis and vitiligo. Furthermore, pooling of the results of cohort studies showed that patients with atopic dermatitis were more likely to develop these autoimmune diseases.

Conclusion: Our meta-analysis showed that patients with atopic dermatitis were at higher risk of multiple autoimmune diseases including alopecia areata, celiac disease, Crohn's disease, rheumatoid arthritis, systematic lupus erythematosus, ulcerative colitis and vitiligo. It is important for early detection of the affected group so that timely management can be initiated. Dermatologists and allergists should be aware of the autoimmune diseases in patients with atopic dermatitis and develop interventions if necessary. Also, limited by the present research, we still require more large-scale studies to further establish the association between atopic dermatitis and autoimmune diseases.
\end{abstract}

\section{Introduction}

Atopic dermatitis (AD), also known as atopic eczema, is the most common chronic inflammatory skin disease characterized by intense itching and recurrent eczematous lesions. Nowadays, AD has become a major public health issues because of its high prevalence, considerable patient-burden as well as increased healthcare utilization. Meanwhile, AD brought huge

*Correspondence: daniluo2005@163.com Department of Dermatology, The First Affiliated Hospital of Nanjing Medical University, Nanjing, China economic burden to patients. To date, AD has affected at least 230 million people worldwide and being the leading cause of the non-fatal disease burden within skin conditions [1-4]. Potential mechanisms included epidermal barrier dysfunction, immune dysregulation and alteration of microbiome, which were modulated by genetic and environmental factors [5]. It has been reported that $\mathrm{AD}$ may be associated with allergic comorbidities including asthma, allergic rhinitis, food allergy and non-allergic comorbidities including psychological disorders, cardiovascular disorders, original author(s) and the source, provide a link to the Creative Commons licence, and indicate if changes were made. The images or other third party material in this article are included in the article's Creative Commons licence, unless indicated otherwise in a credit line to the material. If material is not included in the article's Creative Commons licence and your intended use is not permitted by statutory regulation or exceeds the permitted use, you will need to obtain permission directly from the copyright holder. To view a copy of this licence, visit http://creativecommons.org/licenses/by/4.0/. The Creative Commons Public Domain Dedication waiver (http:// creativecommons.org/publicdomain/zero/1.0/) applies to the data made available in this article, unless otherwise stated in a credit line to the data. 
metabolic syndrome and multiple autoimmune diseases $[6,7]$.

Autoimmune disease is defined as a cluster of more than ninety diseases sharing a common pathogenesis of selfreactive adaptive immune response. Recent large-scale population-based studies have reported the association between $\mathrm{AD}$ and several autoimmune diseases. Paller [6] et al. had reviewed the association between $A D$ with celiac disease, Crohn's disease, ulcerative colitis and alopecia areata. However, this review was not conducted systematically and autoimmune diseases such as systematic lupus erythematosus and vitiligo were not included. So far, there were no systematic review and meta-analysis exploring the link between $\mathrm{AD}$ and multiple autoimmune diseases. Therefore, we performed this systematic review and meta-analysis based on the available literature to investigate the association between $\mathrm{AD}$ and autoimmune diseases.

\section{Methods}

The protocol of this systematic review and metaanalysis was previously registered in the PROSPERO (CRD42020208929). This study was conducted in accordance with the Preferred Reporting Items for Systematic Reviews and Meta-Analyses (PRISMA) guidelines. We searched the PubMed, Embase, and Web of Science databases to identify all relevant studies that reported the association between $\mathrm{AD}$ and autoimmune diseases.

\section{Search strategy}

PubMed, Embase, and Web of Science databases were searched from inception to October 2020 using the following search terms: (atopic dermatitis OR atopic eczema OR atopy) AND (autoimmune diseases OR autoimmune disorders OR autoimmunity OR autoantibody OR alopecia areata OR ankylosing spondylitis OR autoimmune hepatitis OR autoimmune hepatitis OR autoimmune thyroid diseases OR celiac disease OR Crohn's disease OR diabetes OR Grave's disease OR primary immune thrombocytopenia OR multiple sclerosis OR pernicious anemia OR rheumatoid arthritis OR Sjögren's syndrome OR systematic lupus erythematosus OR systematic sclerosis OR ulcerative colitis OR urticaria OR vitiligo).

\section{Study selection}

Studies were included if they met the following criteria: (i) cross-sectional or case-control studies reporting the prevalence of autoimmune diseases in patients with AD compared with controls, or raw data from which we could derive crude ORs with $95 \% \mathrm{CI}$; (ii) cohort studies reporting the incidence of autoimmune diseases in patients with $\mathrm{AD}$ compared with controls, or raw data from which we could derive crude RRs with 95\% CI; (iii) Study groups had a clear definition of AD or atopic eczema, rather than dermatitis or eczema; (iv) Assessments of $\mathrm{AD}$ and autoimmune diseases included ICD, diagnosis of physicians, medical records which recorded physician-diagnosed $\mathrm{AD}$ or autoimmune diseases and questionnaire which included question such as "ever had clinician-diagnosed $\mathrm{AD}$ or autoimmine diseases"; (v) Articles were included if they were published in English, conducted in humans and available in full-text. Studies were excluded if they were reviews, meta-analyses, letters, case reports, comments and guidelines.

\section{Data extraction and quality assessment}

We extracted surname of the first author, publication year, country/region, study design, demographic characteristics (numbers, age and female sex proportion) in the case and control groups, assessment used for $\mathrm{AD}$ and autoimmune diseases, risk estimates with 95\% CI and corresponding adjustments for confounders. The methodological quality of selected studies was evaluated using the Newcastle-Ottawa Scale (NOS), which comprised three main items including sample selection, comparability and exposure/outcome. [8] Studies could be awarded a maximum of one star for each numbered item within the selection and exposure/outcome categories and a maximum of two stars for comparability category, with a score of 1-3, 4-6, and 7-9 represented as of low, intermediate, and high quality respectively. Two authors independently conducted quality assessments of the included studies. Discrepancies were discussed and resolved by the authors.

\section{Statistical analysis}

Separate Random-effects meta-analysis with the inverse variance method was conducted for the association between $\mathrm{AD}$ with alopecia areata, celiac disease, Crohn's disease, rheumatoid arthritis, systematic lupus erythematosus, ulcerative colitis and vitiligo. Randomeffects model was applied because of a wide range of settings in different populations. We preferentially extracted and pooled adjusted risk estimates with 95\% CI from primary studies. If these data were not available, we then derived crude risk estimates with 95\% CI using raw data. Pooled ORs with 95\% CI were calculated for crosssectional and case-control studies and pooled RRs with 95\% CI was calculated for cohort studies. Heterogeneity of included studies was assessed with the Cochran Q statistic, with a $p$ value less than 0.10 suggesting evidence of heterogeneity. Further, the magnitude of heterogeneity was measured using the $I^{2}$ statistic, with values of 
$25-49 \%, 50-75 \%$ and greater than $75 \%$ representing low, moderate and high heterogeneity respectively. All analyses were performed in STATA version 15.0 (Stata Corp, College Station, TX, USA) and Review Manager version 5.3 (The Cochrane Collaboration, London, UK).

\section{Result}

Figure 1 illustrated the process of study selection by the PRISMA flow chart. A total of 5327 articles were identified after removing the duplicates through the initial database search. After review of titles and abstracts, 5286 articles did not meet our inclusion criteria and 41 articles were left for full-text screening. After reading the full texts, 10 articles were excluded because of irrelevant data, three articles were excluded because of unclear control group, five articles were excluded because of unspecific allergic diseases, four articles were letters and five articles were meta-analysis. Eventually, 14 records were included in this qualitative and quantitative synthesis.

\section{Study characteristics}

Table 1 detailed the characteristics of included studies. A total of 14 studies were included in this review. The publication year ranged from 2014 to 2020 . 90,568,121 patients with AD and 101,324,307 controls were included. For study location, six studies were from Europe [9-14], five studies were from Asia [15-19] and three studies [20-22] were from North America. In addition, the assessments of $\mathrm{AD}$ and autoimmune diseases included ICD-9 or 10, diagnosis of dermatologists or physicians, medical records and questionnaire by self-reported. Risk of bias assessment revealed using the Newcastle-Ottawa Scale revealed that 11 included studies were high quality and three studies were moderate quality (Fig. 2). Figure 3 provided the forest plot for the prevalence and incidence of mutiple autoimmune diseases in patients with $\mathrm{AD}$

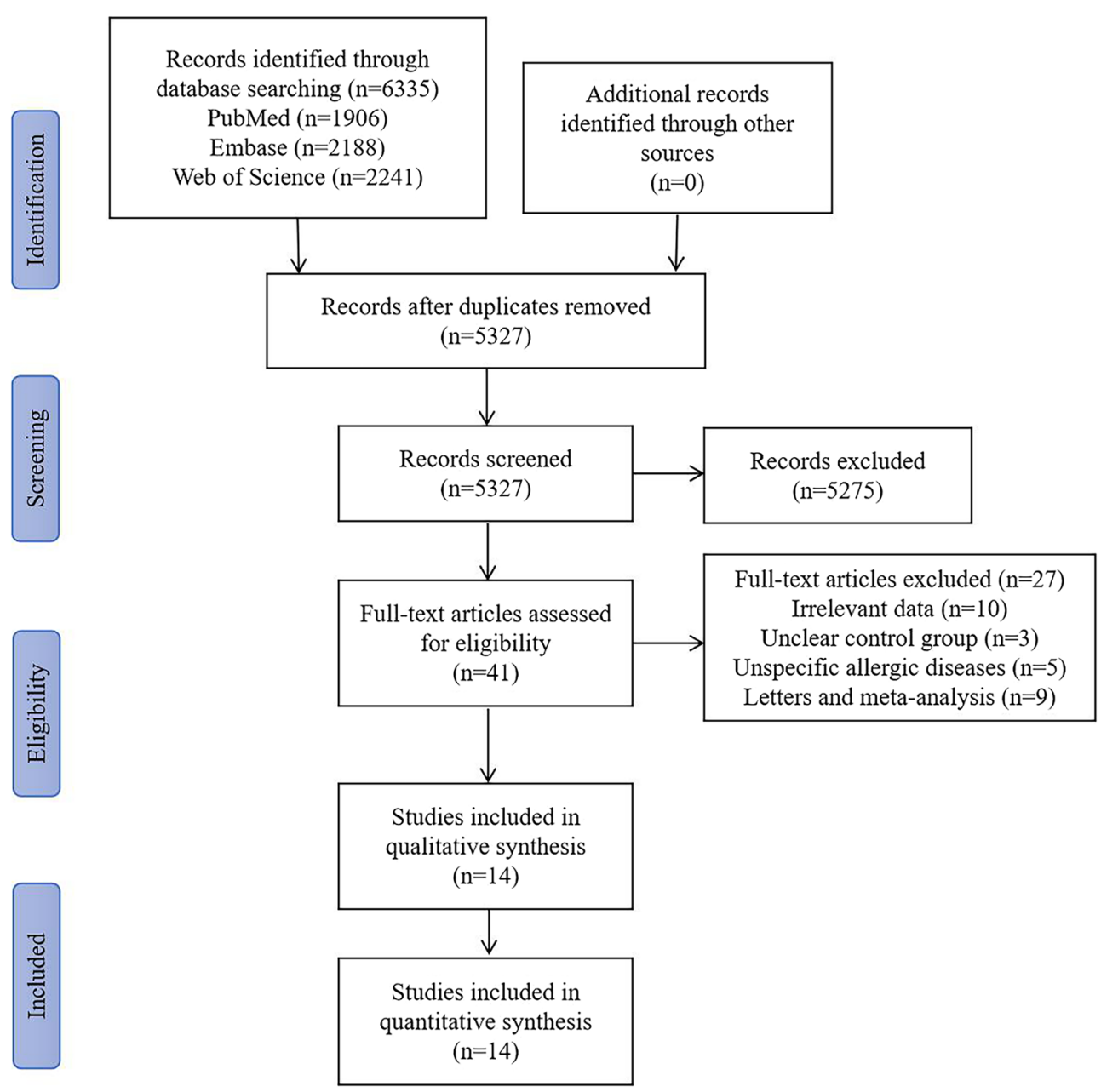

Fig. 1 PRISMA flow chart of the search strategy 


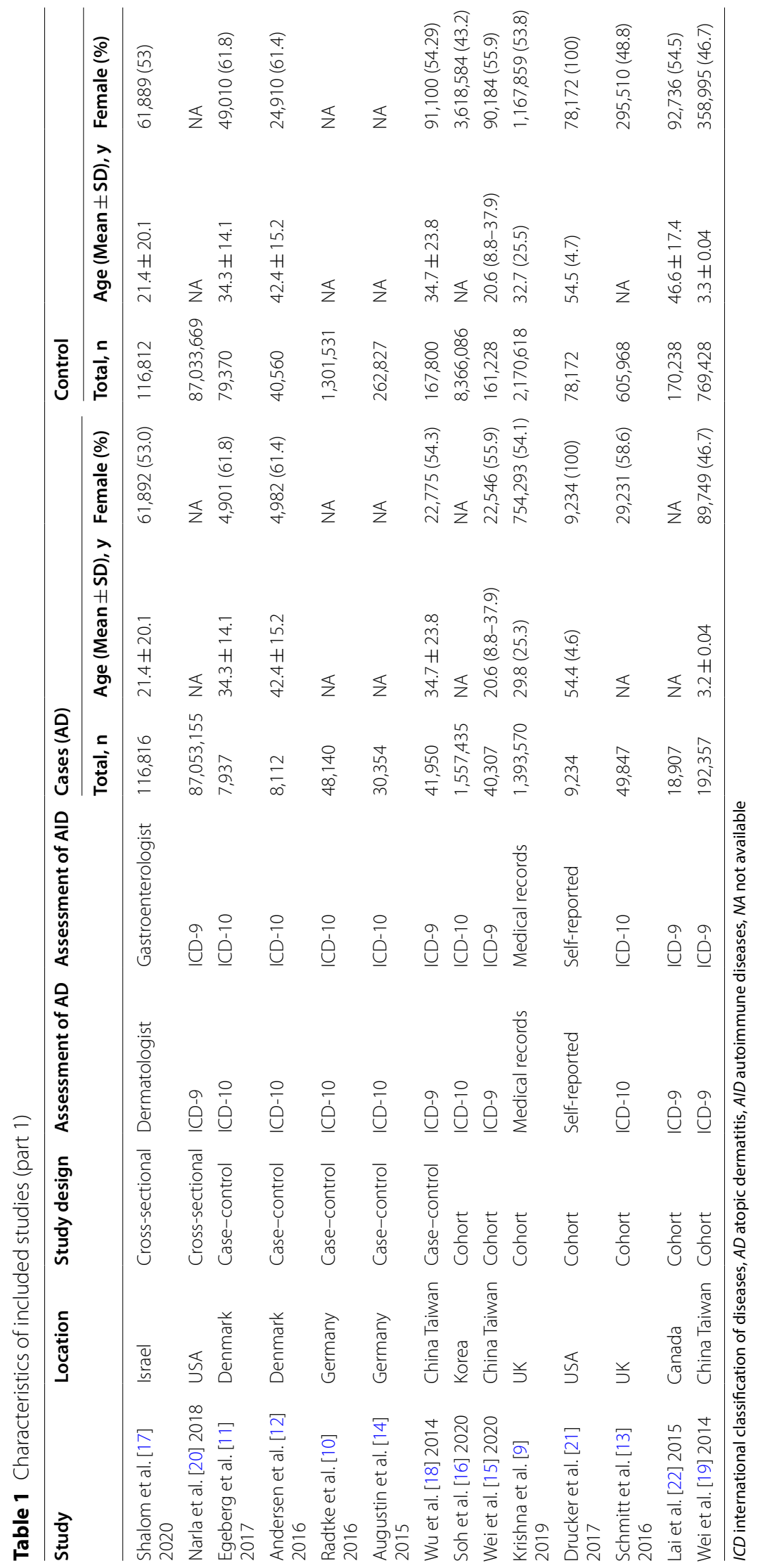




\begin{tabular}{|c|c|c|c|c|}
\hline Cross-sectional study & Selection & Comparability & Exposure & Total quality score \\
\hline Shalom et al, ${ }^{22} 2020$ & $* * * *$ & $*$ & $* * *$ & 8 \\
\hline Narla et al, ${ }^{29} 2018$ & $* * * *$ & $*$ & $* * *$ & 8 \\
\hline \multicolumn{5}{|l|}{ Case-control study } \\
\hline Egeberg et al, ${ }^{10} 2017$ & $* * * *$ & * & $* *$ & 7 \\
\hline Andersen et al, ${ }^{11} 2016$ & $* * * *$ & * & $* *$ & 7 \\
\hline Radtke et al, ${ }^{9} 2016$ & $* * *$ & $*$ & $* *$ & 6 \\
\hline Augustin et $a l,{ }^{13} 2015$ & $* *$ & * & $* *$ & 5 \\
\hline Wu et al, ${ }^{25} 2014$ & $* * * *$ & $*$ & $* *$ & 7 \\
\hline Cohort study & Selection & Comparability & Outcome & Total quality score \\
\hline Soh et $\mathrm{al}^{21} 2020$ & $* * * *$ & $*$ & $* * *$ & 8 \\
\hline Wei et $\mathrm{al}^{20} 2020$ & $* * * *$ & * & $* * *$ & 8 \\
\hline Krishna et al, ${ }^{8} 2019$ & $* * *$ & $*$ & $* * *$ & 7 \\
\hline Drucker et al, ${ }^{31} 2017$ & $* * *$ & $*$ & $*$ & 5 \\
\hline Schmitt et al, ${ }^{12} 2016$ & $* * * *$ & $*$ & $* * *$ & 8 \\
\hline Lai et al, ${ }^{32} 2015$ & $* * * *$ & $*$ & $* * *$ & 8 \\
\hline Wei et $\mathrm{al}^{25} 2014$ & $* * * *$ & $*$ & $* * *$ & 8 \\
\hline
\end{tabular}

Fig. 2 Methodological quality of selected studies by Newcastle-Ottawa Scale (NOS)

compared to control patients. The effect size and corresponding adjustment was also provided (Table 2).

\section{Association between AD and alopecia areata}

Four studies compared the prevalence of alopecia areata in AD patients and controls [10, 12, 14, 20]. Meta-analysis showed a significantly higher prevalence of alopecia areata in $\mathrm{AD}$ patients compared to the controls, with a pooled OR of 9.72 (95\% CI 4.38-21.59). There was high statistical heterogeneity $\left(I^{2}=95.2 \%, \mathrm{p}=0.000\right)$. Further, the pooling of the results from three cohort studies that reported the incidence showed that $\mathrm{AD}$ increased the risk of developing alopecia areata (RR 2.98 95\% CI 1.366.53) $[9,15,21]$. High statistical heterogeneity was also detected $\left(I^{2}=95.9 \%, \mathrm{p}=0.000\right)$ (Fig. 3A and Table 3).

\section{Association between AD and systematic lupus erythematosus}

The prevalence of systematic lupus erythematosus in AD and controls was reported in four studies $[9,12,18,20]$. Patients with AD had a higher prevalence of systematic lupus erythematosus compared to controls, with an OR of 1.74 (95\% CI 1.34-2.19 $\left.I^{2}=71.2 \%, \mathrm{p}=0.008\right)$. Similarly, the incidence of systematic lupus erythematosus in AD and controls was reported in two cohort studies, with an average RR of 2.20 (95\% CI 1.44-3.38, $I^{2}=71.8 \%$, $\mathrm{p}=0.060$ ), indicating an increased risk of developing systematic lupus erythematosus in AD patients (Fig. 3B and Table 3) $[9,19]$.

\section{Association between $A D$ and vitiligo}

Six studies revealed the increased prevalence of vitiligo in AD compared to controls (OR 4.52 95\% CI 2.51-8.13, $\left.I^{2}=96.3 \%, \mathrm{p}=0.000\right)[9,10,12,14,18,20]$. Two cohort studies reported the elevated incidence of vitiligo in $\mathrm{AD}$ compared to controls, which showed AD patients were more likely to develop vitiligo (RR 1.64 95\% CI 1.27-2.13, $\left.I^{2}=37.7 \%, \mathrm{p}=0.207\right)($ Fig. 3C) $[9,21]$.

\section{Association between AD and celiac disease}

Prevalence of celiac disease in $\mathrm{AD}$ and controls was reported in four studies [9, 12, 17, 20]. Meta-analysis showed a higher prevalence of celiac disease in $\mathrm{AD}$ compared to controls. The synthesized OR was 1.98 (95\% CI $1.51-2.60)$ with high heterogeneity $\left(I^{2}=86.7 \%\right.$, $\mathrm{p}=0.000$ ). Only one cohort reported an increased incidence of celiac disease in AD, with a RR of 1.41 (95\% CI 1.32-1.50) (Fig. 3D and Table 3) [9].

\section{Association between AD and Crohn's disease}

Pooling result of five studies estimated an elevated prevalence of Crohn's disease in $\mathrm{AD}$ compared to controls, with an average OR of 1.66 (95\% CI 1.50-1.84, $\left.I^{2}=6.7 \%, \mathrm{p}=0.374\right)[10-12,14,20]$. Three cohort studies further detected an increased incidence of Crohn's disease in AD, with a pooled RR of 1.38 (95\% CI 1.17$1.63, I^{2}=0.0 \%, \mathrm{p}=0.426$ ) (Fig. $3 \mathrm{E}$ and Table 3), indicating that patients with $\mathrm{AD}$ had higher risk of developing Crohn's disease $[9,13,16]$. 


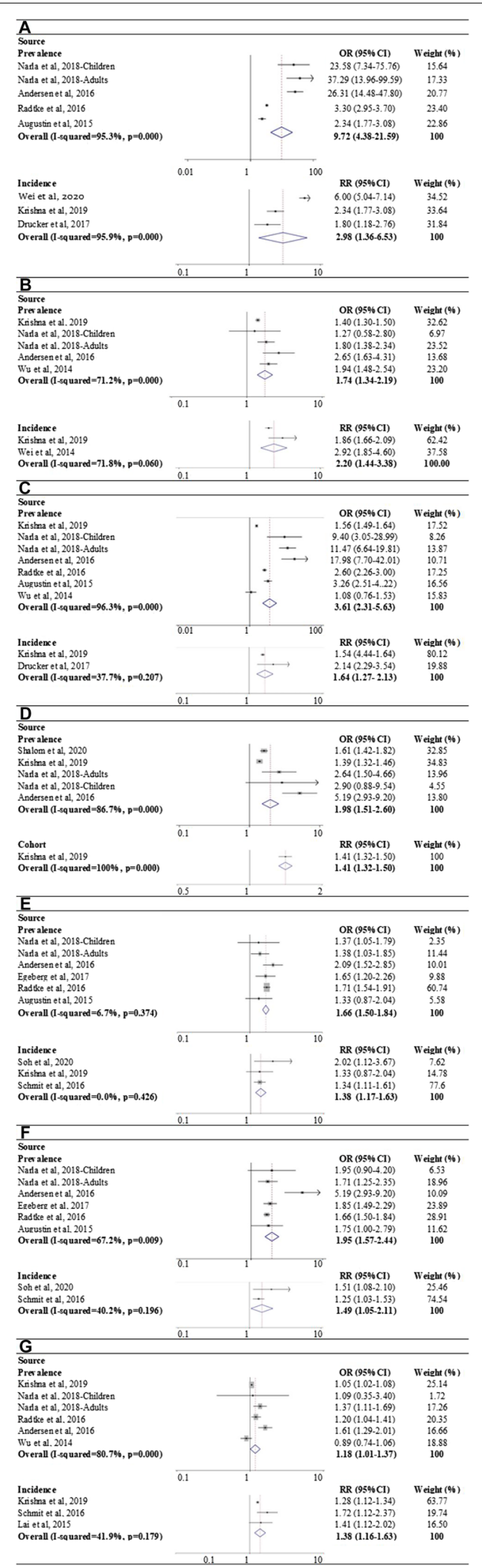

Fig. 3 Forest plot for the prevalence and incidence of mutiple autoimmune diseases in AD compared to controls

\section{Association between $A D$ and ulcerative colitis}

A total of five studies [10-12,14, 20] and two cohort studies $[13,16]$ were included in this analysis. The prevalence and incidence were higher in $\mathrm{AD}$ compared with control, with a pooled OR of 1.95 (95\% CI $1.57-$ $\left.2.44, I^{2}=67.2 \%, \mathrm{p}=0.009\right)$ and a pooled RR of $1.49(95 \%$ CI $1.05-2.11, I^{2}=40.2 \%, \mathrm{p}=0.196$ ) respectively (Fig. $3 \mathrm{~F}$ and Table 3$)$. These results showed that AD increased the risk of developing ulcerative colotis.

\section{Association between $A D$ and rheumatoid arthritis}

Five studies $[9,10,12,18,20]$ reported the prevalence and three cohort studies $[9,13,22]$ reported the incidence of rheumatoid arthritis in patients with AD. The prevalence of rheumatoid arthritis was higher in AD compared to control (OR $1.1895 \%$ CI 1.01-1.37, $I^{2}=80.7 \%, \mathrm{p}=0.000$ ). The incidence was also higher in AD compared to control, with an average RR of 1.38 (95\% CI 1.16-1.63, $I^{2}=41.9 \%, \mathrm{p}=0.179$ ) (Fig. $3 \mathrm{G}$ and Table 3), which meant $\mathrm{AD}$ could increased the risk of developing rheumatoid arthritis.

\section{Discussion}

To date, the mechanism of association between $\mathrm{AD}$ and autoimmune diseases is not clear. Several possible explanations should be noted. Atopic dermatitis is characterized by cutaneous inflammation due to abnormalities of innate immune responses and autoimmune diseases result from a complex dysregulation of innate and adaptive immunity. Common immunologic pathways might be shared in both atopic dermatitis and autoimmune diseases. Interestingly, TH1/TH17 signaling have been presented in both atopic dermatitis and several autoimmune diseases, including SLE, IBD and RA [23, 24]. Genetic association might be another possible explanation. A recent meta-analysis of genome-wide association studies based on 21,000 cases and 95,000 controls identified 10 new susceptibility loci for atopic dermatitis. All novel susceptibility loci were associated with autoimmune regulation and there were substantial genetic overlaps with multiple autoimmune diseases [25]. Additionally, it has been reported that $\mathrm{AD}$, vitiligo responded to inhibition of the JAK-STAT pathway [26, 27]. Despite these possible common pathophysiology, the correlation of AD with autoimmune diseases has been rarely studied. Identification of common mechanisms between $\mathrm{AD}$ and autoimmune diseases might provide common therapeutic approaches for both diseases.

This is the first and most comprehensive systematic review and meta-analysis to evaluate the prevalence and incidence between $\mathrm{AD}$ and multiple autoimmune 
Table 2 Characteristics of included studies (part 2)

\begin{tabular}{|c|c|c|}
\hline Study & Effect size $(95 \% \mathrm{Cl})$ & Adjusted for \\
\hline Shalom et al. [17] 2020 & Celiac disease: $\mathrm{aOR}=1.609(1.42-1.82)$ & Age, sex, smoking status and primary care visits \\
\hline Narla et al. [20] 2018 & $\begin{array}{l}32 \text { specific autoimmune diseases: adult (aOR } 1.45 \text { 1.32-1.58); } \\
\text { children (aOR } 2.08 \text { 1.73-2.5) }\end{array}$ & Age, sex, race/ethnicity, and insurance status \\
\hline Egeberg et al. [11] 2017 & $\mathrm{CD}: \mathrm{aOR}=1.65(1.20-2.26) ; \mathrm{UC}: \mathrm{aOR}=1.85(1.49-2.29)$ & $\begin{array}{l}\text { Age, sex, socioeconomic status, and number of dermatologist } \\
\text { visits }\end{array}$ \\
\hline Andersen et al. [12] 2016 & 22 specific autoimmune diseases: overall effect not available & $\begin{array}{l}\text { Age, sex, smoking, socioeconomic status, and number of } \\
\text { dermatologist visits }\end{array}$ \\
\hline Radtke et al. [10] 2016 & $\begin{array}{l}\mathrm{CD}: \mathrm{OR}=1.71(1.54-1.91) ; \mathrm{UC}: \mathrm{OR}=1.66(1.50-1.84) ; \mathrm{AA}: \\
\mathrm{OR}=3.30(2.95-3.70) ; \text { vitiligo: } \mathrm{OR}=2.60(2.26-3.00)\end{array}$ & NA \\
\hline Augustin et al. [14] 2015 & $\begin{array}{l}\mathrm{CD}: \mathrm{OR}=1.33 \text { (0.87-2.04); } \mathrm{UC}: \mathrm{OR}=1.75(1.10-2.79) ; \mathrm{AA}: \\
\mathrm{OR}=2.34(1.77-3.08) ; \text { vitiligo: } \mathrm{OR}=3.26(2.51-4.22)\end{array}$ & NA \\
\hline Wu et al. [18] 2014 & $\begin{array}{l}\text { T1DM: aOR = } 1.00(0.90-1.13) ; \mathrm{PA}: \mathrm{aOR}=0.54(0.20-1.41) ; \mathrm{RA}: \\
\mathrm{aOR}=0.89(0.74-1.06) ; \mathrm{SLE}: \mathrm{aOR}=1.94(1.48-2.54) ; \text { vitiligo: } \\
\mathrm{aOR}=1.08(0.76-1.53) ; \mathrm{ATD}: \mathrm{aOR}=0.93(0.76-1.14)\end{array}$ & $\begin{array}{l}\text { Age, gender, number of healthcare visits, presence of allergic } \\
\text { rhinitis, asthma and the autoimmune disorders listed in this } \\
\text { table }\end{array}$ \\
\hline Soh et al. [16] 2020 & $C D: a R R=2.02(1.12-3.67) ; U C: a R R=1.51(1.08-2.10)$ & $\begin{array}{l}\text { Age, sex, residence, smoking history, alcohol consumption, } \\
\text { regular exercise, income, body mass index, diabetes, } \\
\text { hypertension, and dyslipidemia }\end{array}$ \\
\hline Wei et al. [15] 2020 & $A A: a R R=6.00(5.04-7.14)$ & \\
\hline Krishna et al. [9] 2019 & $\begin{array}{l}C D: a R R=1.33 \text { (0.87-2.04); UC: } a R R=1.75(1.10-2.79) ; \\
\text { AA: aRR=2.34 (1.77-3.08); vitiligo: aRR=1.67 (1.50-1.87); } \\
\text { Sjogrens syndrome: } a R R=1.52(1.22-1.88) ; R A: a R R=1.31 \\
\text { (1.22-1.41); PA: aRR=1.23 (1.11-1.35); MG: aRR=1.04 (0.76- } \\
\text { 1.41); celiac disease: aRR=1.37 (1.24-1.52); ATD: aRR=1.14 } \\
\text { (1.00-1.30); multiple sclerosis: aRR=1.15 (0.96-1.37); SLE: } \\
\text { aRR }=2.40 \text { (1.98-2.91) }\end{array}$ & $\begin{array}{l}\text { Age, sex, socio-economic status, smoking status, BMI and } \\
\text { ethnicity }\end{array}$ \\
\hline Drucker et al. [21] 2017 & AA: aRR = 1.80 (1.18-2.76); vitiligo: aRR=2.14 (2.29-3.54) & $\begin{array}{l}\text { Age, BMl, alcohol intake, physical activity, cigarette smoking } \\
\text { status and history of postmenopausal hormone replacement } \\
\text { use }\end{array}$ \\
\hline Schmitt et al. [13] 2016 & $\begin{array}{l}C D: a R R=1.34(1.11-1.61) ; U C: a R R=1.25(1.03-1.53) ; R A: \\
a R R=1.72(1.12-2.37) ; T 1 D M: a R R=0.72(0.53-0.998)\end{array}$ & $\begin{array}{l}\text { Age, sex, socioeconomic status, access to health care and } \\
\text { health care utilization behavior }\end{array}$ \\
\hline Lai et al. [22] 2015 & $\mathrm{RA}: \mathrm{aRR}=1.41(0.98-2.02)$ & Age, sex, urbanization level, income and diabetes mellitus \\
\hline Wei et al. [19] 2014 & SLE: $a R R=2.92(1.85-4.60)$ & $\begin{array}{l}\text { Sex, age, urbanization, and mutual five allergic diseases } \\
\text { (asthma, allergic rhinitis, allergic conjunctivitis, atopic } \\
\text { dermatitis and urticaria) }\end{array}$ \\
\hline
\end{tabular}

$A A$ alopecia areate, $C D$ Crohn's disease, $R A$ rheumatoid arthritis, $S L E$ systematic lupus erythematosus, UC ulcerative colitis, aOR adjusted odds ratio, $C I$ confidence interval, aRR adjusted relative risk

Table 3 Results of pooling odds ratio and risk ratio of includied studies

\begin{tabular}{|c|c|c|c|c|c|c|}
\hline \multirow[t]{2}{*}{ Type of autoimmune disease } & \multicolumn{3}{|c|}{ Cross-sectional/case-control studies } & \multicolumn{3}{|c|}{ Cohort studies } \\
\hline & Studies(n) & Case/control(n) & OR $(95 \% \mathrm{Cl})$ & Studies(n) & Case/control(n) & $\mathrm{RR}(95 \% \mathrm{Cl})$ \\
\hline Alopecia areata & 4 & $87,139,761 / 88,638,587$ & $9.72(4.38-21.59)$ & 3 & $1,443,111 / 2,410,018$ & $2.98(1.36-6.53)$ \\
\hline Systematic lupus erythematosus & 4 & $88,496,787 / 89,412,647$ & $1.74(1.34-2.19)$ & 2 & $1,585,927 / 2,940,046$ & $2.20(1.44-3.38)$ \\
\hline Vitiligo & 6 & $88,529,196 / 89,676,032$ & $3.61(2.31-5.63)$ & 2 & $1,402,804 / 2,248,790$ & $1.64(1.27-2.13)$ \\
\hline Celiac disease & 4 & $88,571,653 / 89,361,659$ & $1.98(1.51-2.60)$ & 1 & $1,393,570 / 2,170,618$ & $1.41(1.32-1.50)$ \\
\hline Crohn's disease & 5 & $87,101,613 / 87,416,984$ & $1.66(1.50-1.84)$ & 3 & $3,000,852 / 2,776,586$ & $1.38(1.17-1.63)$ \\
\hline Ulcerative colitis & 5 & $87,101,613 / 87,416,984$ & $1.95(1.57-2.44)$ & 2 & $1,607,282 / 8,972,054$ & $1.49(1.05-2.11)$ \\
\hline Rheumatoid arthritis & 5 & $88,527,141 / 89,675,474$ & $1.18(1.01-1.37)$ & 3 & $1,462,324 / 2,946,824$ & $1.38(1.16-1.63)$ \\
\hline
\end{tabular}

diseases, which included alopecia areata, celiac disease, Crohn's disease, rheumatoid arthritis, systematic lupus erythematosus, ulcerative colitis and vitiligo. A previous systematic review and meta-analysis conducted by
Mohan et al. [28] found a higher risk of AD in patients with either vitiligo (OR 7.82, 95\% CI 3.06-20.00) or alopecia areata (OR 2.57, 95\% CI 2.25-2.94). However, it was not clear whether $\mathrm{AD}$ was at increased risk of 
vitiligo or alopecia areata. In our meta-analysis, we further explore the association between $\mathrm{AD}$ with vitiligo and alopecia areata. Acharya et al. [29] further explored the prevalence and incidence of vitiligo in AD. Results revealed significant association between $\mathrm{AD}$ and vitiligo (OR 3.21, 95\% CI 1.90-5.43). In a cohort included in this meta-analysis, the prevalence and incidence of autoimmune diseases were both provided. However, the prevalence of the included cohort was not pooled in the meta-analysis. We then calculated the OR with $95 \%$ CI and added it to the pooled meta-analysis. In addition, the other two meta-analysis suggested a bidirectional relationship between $\mathrm{AD}$ and inflammatory bowel diseases including Crohn's disease and ulcerative colitis $[30,31]$.

\section{Limitation}

Several limitations should be emphasized. Firstly, limited by the number of included studies, subgroup analyses stratified by age, sex, subset and severity of AD were not performed. Secondly, we found minimal publication bias in two meta-analyses, which might result from flawed methodologic design in studies with small sample size. Thirdly, though the fully adjusted estimate effects with 95\% CI were extracted, the adjusted confounding factors (such as smoking, use of medication and socioeconomic status) were inconsistent among the included studies. Several included studies were of small sample size with moderate methodological quality. The assessments of $\mathrm{AD}$ and autoimmune disorders in part of studies were based on questionnaires, which might lead to misdiagnosis of these diseases. Additionally, only English articles were included due to the authors' language restriction and studies in other languages might be missed, which could lead to potential bias in our results.

\section{Future practice}

Further research is needed to identify whether the subset and severity of $\mathrm{AD}$ are at elevated risk for autoimmune diseases. In addition, not all autoimmune diseases were analyzed, therefore we require more large-scale studies to further establish the association between AD and more autoimmune diseases. Future research is also needed to assess the risk factors such as medication treatments for comorbid autoimmune diseases in patients with $\mathrm{AD}$. The underlying mechanism of the association between $\mathrm{AD}$ and autoimmune comorbidities should also be established. Moreover, clinicians especially allergists and dermatologists should be aware of the autoimmune diseases in patients with $\mathrm{AD}$ and develop interventions to screen and monitor for them.

\section{Conclusion}

We performed a systematic review and meta-analysis of observational studies which included 90,568,121 patients with $\mathrm{AD}$ and 101,324,307 controls to examine the association between $\mathrm{AD}$ with multiple autoimmune diseases. It was founded that $\mathrm{AD}$ was associated with increased risks of alopecia areata, celiac disease, Crohn's disease, rheumatoid arthritis, systematic lupus erythematosus, ulcerative colitis and vitiligo. However, our meta-analyses were based on the limited studies which were of cross-sectional, case-control and retrospective cohort designs. Therefore, more large-scale prospective clinical trials and mechanistic studies were warranted to further elucidate the association between $\mathrm{AD}$ and more autoimmune diseases.

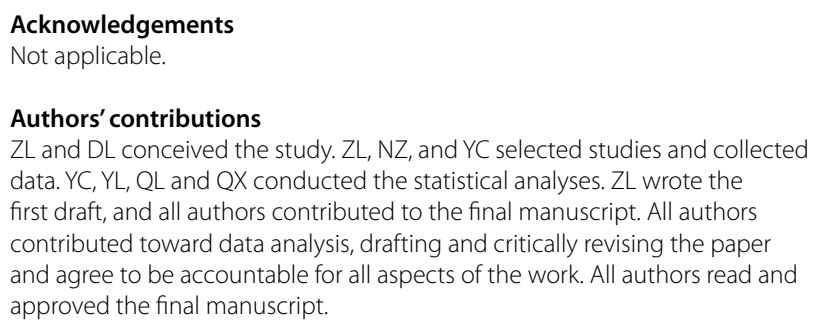

\section{Declarations}

Ethics approval and consent to participate Not applicable.

\section{Consent for publication}

Not applicable.

\section{Competing interests}

The authors declare that they have no competing interests.

Received: 23 March 2021 Accepted: 3 September 2021

Published online: 25 September 2021

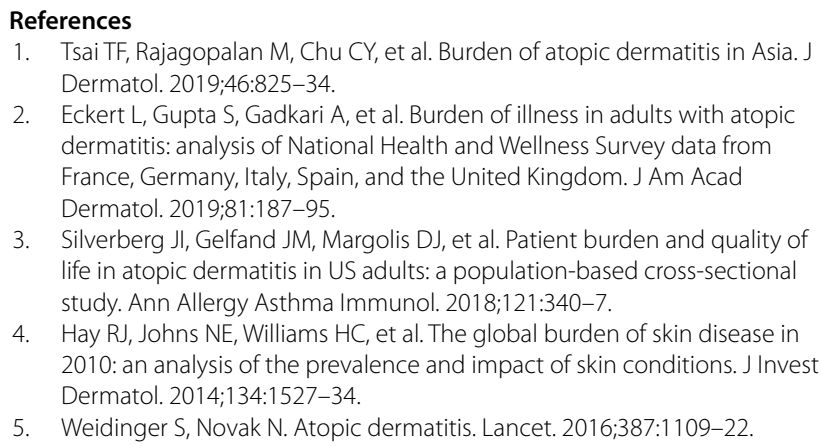

1. Tsai TF, Rajagopalan M, Chu CY, et al. Burden of atopic dermatitis in Asia. J Dermatol. 2019:46:825-34.

2. Eckert L, Gupta S, Gadkari A, et al. Burden of illness in adults with atopic dermatitis: analysis of National Health and Wellness Survey data from France, Germany, Italy, Spain, and the United Kingdom. J Am Acad Dermatol. 2019;81:187-95.

3. Silverberg J, Gelfand JM, Margolis DJ, et al. Patient burden and quality of life in atopic dermatitis in US adults: a population-based cross-sectional study. Ann Allergy Asthma Immunol. 2018;121:340-7.

4. Hay RJ, Johns NE, Williams HC, et al. The global burden of skin disease in 2010: an analysis of the prevalence and impact of skin conditions. J Invest Dermatol. 2014;134:1527-34.

5. Weidinger S, Novak N. Atopic dermatitis. Lancet. 2016;387:1109-22. 
6. Paller A, Jaworski JC, Simpson EL, et al. Major comorbidities of atopic dermatitis: beyond allergic disorders. Am J Clin Dermatol. 2018;19:821-38.

7. Silverberg J. Comorbidities and the impact of atopic dermatitis. Ann Allergy Asthma Immunol. 2019;123:144-51.

8. Stang A. Critical evaluation of the Newcastle-Ottawa scale for the assessment of the quality of nonrandomized studies in meta-analyses. Eur J Epidemiol. 2010;25:603-5.

9. Krishna MT, Subramanian A, Adderley NJ, et al. Allergic diseases and longterm risk of autoimmune disorders: Iongitudinal cohort study and cluster analysis. Eur Respir J. 2019. https://doi.org/10.1183/13993003.00476-2019.

10. Radtke MA, Schäfer I, Glaeske G, et al. Prevalence and comorbidities in adults with psoriasis compared to atopic eczema. J Eur Acad Dermatol Venereol. 2017;31:151-7.

11. Egeberg A, Andersen YM, Gislason GH, et al. Prevalence of comorbidity and associated risk factors in adults with atopic dermatitis. Allergy. 2017;72:783-91.

12. Andersen $Y M$, Egeberg $A$, Gislason $G H$, et al. Autoimmune diseases in adults with atopic dermatitis. J Am Acad Dermatol. 2017;76:274-80.e1.

13. Schmitt J, Schwarz K, Baurecht H, et al. Atopic dermatitis is associated with an increased risk for rheumatoid arthritis and inflammatory bowel disease, and a decreased risk for type 1 diabetes. J Allergy Clin Immunol 2016;137:130-6.

14. Augustin M, Radtke MA, Glaeske G, et al. Epidemiology and comorbidity in children with psoriasis and atopic eczema. Dermatology. 2015;231:35-40.

15. Wei $Y H$, Tai YH, Dai $Y X$, et al. Bidirectional association between alopecia areata and atopic dermatitis: a population-based cohort study in Taiwan. Clin Exp Allergy. 2020. https://doi.org/10.1111/cea.13729.

16. Soh H, Lee HJ, Han K, et al. Atopic diseases are associated with development of inflammatory bowel diseases in Korea: a nationwide population-based study. Clin Gastroenterol Hepatol. 2020. https://doi. org/10.1016/j.cgh.2020.07.049.

17. Shalom G, Kridin K, Raviv KO, et al. Atopic dermatitis and celiac disease: a cross-sectional study of 116,816 patients. Am J Clin Dermatol. 2020;21:133-8.

18. Wu LC, Hwang CY, Chung PI, et al. Autoimmune disease comorbidities in patients with atopic dermatitis: a nationwide case-control study in Taiwan. Pediatr Allergy Immunol. 2014;25:586-92.

19. Wei CC, Lin CL, Tsai JD, et al. Increased Incidence of juvenile onset systemic lupus erythematosus in children with atopic dermatitis. Lupus. 2014:23:1494-9.
20. Narla S, Silverberg JI. Association between atopic dermatitis and autoimmune disorders in US adults and children: a cross-sectional study. J Am Acad Dermatol. 2019;80:382-9.

21. Drucker AM, Thompson JM, Li WQ, et al. Incident alopecia areata and vitiligo in adult women with atopic dermatitis: Nurses' Health Study 2. Allergy. 2017;72:831-4.

22. Lai NS, Tsai TY, Koo M, et al. Association of rheumatoid arthritis with allergic diseases: a nationwide population-based cohort study. Allergy Asthma Proc. 2015:36:99-103.

23. Wilke CM, Bishop K, Fox D, et al. Deciphering the role of Th17 cells in human disease. Trends Immunol. 2011;32:603-11.

24. Koga C, Kabashima K, Shiraishi N, et al. Possible pathogenic role of Th17 cells for atopic dermatitis. J Invest Dermatol. 2008;128:2625-30.

25. Paternoster L, Standl M, Waage J, et al. Multi-ancestry genome-wide association study of 21,000 cases and 95,000 controls identifies new risk loci for atopic dermatitis. Nat Genet. 2015;47:1449-56.

26. Craiglow BG, King BA. Tofacitinib citrate for the treatment of vitiligo: a pathogenesis-directed therapy. JAMA Dermatol. 2015;151:1110-2.

27. Levy LL, Urban J, King BA. Treatment of recalcitrant atopic dermatitis with the oral janus kinase inhibitor tofacitinib citrate. J Am Acad Dermatol. 2015;73:395-9.

28. Mohan GC, Silverberg II. Association of vitiligo and alopecia areata with atopic dermatitis: a systematic review and meta-analysis. JAMA Dermatol. 2015:151:522-8.

29. Acharya P, Mathur M. Association of atopic dermatitis with vitiligo: a systematic review and meta-analysis. J Cosmet Dermatol. 2020;19:2016-20.

30. Shi X, Chen Q, Wang F. The bidirectional association between inflammatory bowel disease and atopic dermatitis: a systematic review and meta-analysis. Dermatology. 2020. https://doi.org/10.1159/00050 5290.

31. Lee $H$, Lee JH, Koh SJ, et al. Bidirectional relationship between atopic dermatitis and inflammatory bowel disease: a systematic review and meta-analysis. J Am Acad Dermatol. 2020;83:1385-94.

\section{Publisher's Note}

Springer Nature remains neutral with regard to jurisdictional claims in published maps and institutional affiliations.
Ready to submit your research? Choose BMC and benefit from:

- fast, convenient online submission

- thorough peer review by experienced researchers in your field

- rapid publication on acceptance

- support for research data, including large and complex data types

- gold Open Access which fosters wider collaboration and increased citations

- maximum visibility for your research: over 100M website views per year

At BMC, research is always in progress.

Learn more biomedcentral.com/submissions 